\title{
Effectiveness of CRT on Secondary School Students' Attitude towards Cigarette Smoking in Akwa South
}

\author{
LGA \\ Anyamene, Ada; Nwokolo, Chisom Sandra \\ Department of Guidance and Counselling, Faculty of Education, Nnamdi Azikiwe University, Awka, Nigeria
}

\begin{abstract}
This study investigated the effectiveness of CRT on secondary school students' attitude towards cigarette smoking in Akwa South LGA. One research question guided the study while one null hypothesis was tested at 0.05 level of significance. The design for the study was quasi-experimental, non-randomised pre-test and post-test, control group research. The sample comprised 62 students purposively selected from a population of 289 students. Questionnaire on Cigarette Smoking (QCS), an adapted Youth tobacco survey (YTS) and Wisconsin inventory of smoking dependence motive (WISDM-68). was used for data collection. The internal consistency reliability coefficient for the instrument was 0.85 . Data was collected through direct delivery of the instrument to the respondents. Mean scores were used to answer the research questions, while the null hypotheses were tested using Analysis of Co-variance (ANCOVA). The finding of the study revealed among others that Cognitive Restructuring technique was effective in reducing students with prone attitude towards cigarette smoking. It was concluded from the findings that CRT is an effective treatment technique for modifying cigarette smoking among secondary school students in Awka South LGA. Based on the findings and implications of the study, it was recommended that Practicing counsellors and therapist should make use of the cognitive restructuring technique in counselling and therapy of secondary school students to modifying their unhealthy attitude towards cigarette smoking.
\end{abstract}

Keywords: cognitive restructuring technique, attitude, cigarette smoking, effectiveness students

\section{INTRODUCTION}

$\mathrm{C}$ igarette smoking among children of school age had been viewed by parents and school authorities as a disciplinary problem, involving moral standards, age-related prerogatives and vague health warnings. Today, the trend seemed to have changed and smoking among the adolescents seems more like a normal act and an accepted part of growing up. However, with so much available research evidence on the harmful effects of cigarette smoking, the health warnings seems to have become clearer that preventing cigarette use among youths is critical to ending what could be described today as tobacco smoking epidemic in the Nigeria.

Smoking is an action taken by people that are associated with the burning and inhaling of a substance. It is the act of inhaling and exhaling the fumes of burning plants material (Webb Hooper, Rodríguez de Ybarra \& Baker, 2013). It is one of the most common methods of consuming tobacco. In the opinion of Leone, Landini and Leone (2010), it is the inhalation of the smoke of burned tobacco that may occur occasionally or habitually as a consequence of a physical addiction to some chemicals, primarily nicotine. Through the smoking practice, variety of plant materials are smoked including marijuana, hashish but the act seems mostly associated with tobacco as packaged and smoked as a cigarette, cigar or pipe.

A cigarette or cigar as commonly used in some parlance contains a reconstituted tobacco product known as sheets which consists of recycled stems, stalk, scraps, collected dust and floor sweepings to which are added glue, chewed and filtered. The product is then sprayed with nicotine that are extracted from tobacco scraps and shaped into curls (Halonen et al, 2014). In order to smoke, the cigarette is ignited at one end, causing it to smolder and allowing smoke to be inhaled from the other end, which is then held in or to the mouth.

The act of smoking consists of several behaviors which are usually applied to cigarettes. According to Alvarez (2017) it is the practice of burning cigarette and inhaling the smoke into the mouth and then releasing it. Cigarette smoking consists of drawing into the mouth, and usually the lungs, smoke from burning tobacco (West \& Shiffman 2017). In the context of this study, cigarette smoking is the practice of burning tobacco, drawing into the mouth and releasing it.

The primary constituents of tobacco smoke are nicotine, tar (the particulate residue from combustion), and gases such as carbon dioxide and carbon monoxide. The main health effect of nicotine is its addictiveness while that of carbon monoxide is its displacement of oxygen in the body, when it passes from the lungs into the bloodstream. Therefore, when smokers accumulate high levels of carbon monoxide, it would likely starve the body of oxygen and puts an enormous strain on the entire cardiovascular system.

Going by its hazardous effects, cigarette smoking is seen as the largest single risk factor for premature death in both developed and developing countries. According to World Health Organization (WHO, 2017), smoking causes nearly six million deaths worldwide on an annual basis. It has posed as a problem with great impact on individual's well-being, especially among the youths. Chandrupatla, Tavares and Natto 
(2017) noted that smoking cigarette could lead to retardation in physical development and that those who smoke are more likely to be involved in deviant behaviours and likely to engage in the use of illicit drugs and alcohol.

The harmful effects of smoking are not limited to the smoker. The toxic components of tobacco smoke are found not only in the smoke that the smoker inhales, but also in the environment where the tobacco is smoked. This is usually caused by secondhand smoke, that is, the smoke exhaled by the smoker and the smoke that rises directly from the smoldering tobacco. Therefore, nonsmokers who are routinely exposed to environmental tobacco smoke are likely at increased risk also for some of the same diseases that afflict smokers, including lung cancer and cardiovascular disease.

Smokers would most likely have a variety of reasons or motives for smoking. Many people, especially college students smoke in the context of social situations or to enhance their level of self-confidence (Piko, Wills \& Walker, 2017). Some smokers may also engage in smoking due to their perceived notion that it helps them deal with boredom and provides a means for affect regulation, such as using tobacco to calm down or cheer up. Thus, it is the individual beliefs and motives that have the tendency to dictate their attitude towards smoking.

Attitude is a psychological construct, a mental and emotional entity that is inherent in, or characteristics of a person (Perloff, 2016). It is an individual's predisposed state of mind regarding a value and it is precipitated through a responsive expression towards a person, place, thing or event which in turn influences the individual's thought and action (Cacioppo, Cacioppo \& Pety, 2018). Attitude is thus a hypothetical construct that represents an individual's like and dislike for an item. It is positive when a person is well disposed towards an object or a person and negative when a person does not have good feelings, thought or reactions towards an object or person. Hence, in the context of this study, attitude towards cigarette smoking is described as students' thought, ideas, feelings or emotions that might predispose them to engage in cigarette smoking.

attitude $\begin{gathered}\text { Vogel, Bohner and Wanke (2014) noted that an } \\ \text { contains }\end{gathered}$ and behavioural components. The affective component of attitudes refers to ones feelings or emotions linked to an attitude object. Affective responses influence attitudes in a number of ways. For example, someone maybe afraid of cockroach, so this negative affective response is likely to cause the person to have a negative attitude towards cockroaches. The behavioural component of attitudes refers to the way the attitude people have influences how they act or behave. The cognitive component of attitudes on the other hand refers to the beliefs, thoughts, and attributes that people would associate with an object. This perhaps could explain why cognitive restructuring therapies are often used as a psychological treatment to address the interactions between thoughts, emotions, and behaviour.
Cognitive restructuring include treatments and practices as noted by Beck (2011) and Somers (2017) which share fundamental propositions. For example; that peoples' cognitions affects what they feel and how they choose to behave, and that desired behaviour change may be affected through changes in the individual's cognitions. Beck noted that psychological problems, such as couple and family problems, and medical problems with psychological components, such as chronic pain, tinnitus, and insomnia are also treated by cognitive restructuring therapy. Going by its efficacious claims, it could also be used to modify students' attitude towards cigarette smoking.

Somers (2017) defined cognitive restructuring as employing self-statements, arguments, and disputations to make the client see irrationality in his or her behaviour and to be able to devise alternative ways to such irrationality in case the urge arises in the future. It is a type of treatment that is based firmly on research findings in which the approach could aid people in achieving specific changes or goals. Such changes or goals might involve a way of acting, like smoking less or being more outgoing; a way of feeling, a way of thinking, like learning to problem-solve or get rid of selfdefeating thoughts and a way of dealing with physical or psychological problems through exposure to counselling and therapy. In the context of this study, cognitive restructuring refers to the use of self-statements, arguments, and disputations to make a client understand the irrationality in his or her behaviour and be able to develop alternative ways to deal with such irrationality even as the urge arises in the future.

The goal of cognitive restructuring in this study is to replace smoking inducing thoughts of the secondary school students with more rational and positive ones in order to modify their predisposing attitude towards cigarette smoking. It is the belief of the cognitive therapists that cigarette smokers suffer from misconception about themselves. These misconceptions tend to cause psychological problems, depressions which could lead to smoking. The assumption underlying this technique is that behaviour disorders like cigarette smoking addiction could result from inappropriate irrational or self-defeating thoughts or belief. Thus, cognitive restructuring when applied in therapy, will likely address the present problems of students' attitude towards cigarette smoking and would likely help clients to have a better way of evaluating their own thoughts in order to correct them.

Correcting a deeply rooted negative lifestyle like cigarette smoking often requires professional help. Though, one of the key challenges to treatment of such people who have become dependent to cigarette smoking is that in Nigeria, they are often referred to medical treatment instead of psychological treatment. Physicians and health professionals on their own part tend to pay limited attention to changing the unhealthy attitude behind the habits of such patients. Instead, they may end up providing only the knowledge of the health 
risks of such unhealthy habits and appeal to the good intentions of the patients.

Knowledge of the risks of unhealthy habits and good intentions to change are only a prerequisite but not enough to change unhealthy habits for most patients. It may be sufficient for the minority of patients who are ready to change, but it is only the first of many steps needed for the majority of patients who are reluctant or ambivalent about the change. Such persons require relationship and dialogue and not necessarily issues for medicine. An abiding commitment of a counsellor or therapist to appreciate and foster client's own competencies and self-confidence tend to lead to a relation based on trust and hope. Hence, building up a healing relationship may be required for the client to become a co-producer of his or her health. Based on the above point of view, behavioural and cognitive counselling interventions like cognitive restructuring seem necessary to modify attitude towards cigarette smoking.

\section{Statement of the Problem}

The basic premise of cognitive restructuring is that people can learn new behaviors to use in response to stimuli and that the thought processes that serve as an intermediate step between the stimuli and the behavior can be altered, thereby, influencing the individual's attitude towards smoking. This approach has been used in the treatment of a wide range of psychological disorders, including tobacco smoking.

A study conducted by Yunusa, Abdullahi, Oliagba, Sani and Umma (2014) for instance investigated the effect of Cognitive Restructuring Intervention Program on tobacco smoking among adolescents in senior secondary school. Findings indicate that the treatment significantly affected tobacco use cessation. Similarly, study conducted by Raja, Saha, Mohd, Narang, Reddy, Kumari (2014) on Cognitive Behavioural Therapy versus basic health education for tobacco cessation among tobacco users also found that such cognitive therapies may change smoking abstinence rate as compared to other interventions.

This technique has been widely used in treatment of behavioural disorders such as used in studies such as Hargiana and Keliat (2018) and Oguzie, Ani, Obi and Onyegirim (2018) and had indicated the efficacy of cognitive restructuring therapy in modifying some maladaptive behaviour of students in Nigeria. However, not much has been done in applying cognitive restructuring in treating maladaptive behaviour such as cigarette smoking of students in in Awka South Local Government area of Anambra State. It is therefore the belief of this researcher that since the technique has proven its efficacy in treating other behavioural disorders, it could also be effective in modifying students' attitude towards cigarette smoking. Hence, there is need for this study to investigate the effectiveness of the technique on secondary school students' attitude towards cigarette smoking in Awka South Local Government Areas.

\section{Purpose of the Study}

The purpose of this study is to determine the effectiveness of CRT on secondary school students' attitude towards cigarette smoking in Akwa South LGA. Specifically, the study sought to determine the;

1. Effectiveness of CRT on secondary school students' attitude towards cigarette smoking when compared to those in the control group, using the difference in the pretest and posttest mean attitude scores of the students.

\section{Significance of the Study}

The findings of this study will be of benefit to the students, teachers, counselors, parents, universities and future researchers.

The finding of this study will be of benefit to the students. The finding of this study when published could motivate the school to organize group interactive counselling sessions where issues related to cigarette smoking will be discussed. This will likely enlighten the students to be acquainted with the adverse effect of cigarette smoking and how they could be helped through counselling.

\section{Research Questions}

The following research questions guided the study

1. What is the effect of Cognitive Restructuring technique on secondary school students' attitude towards cigarette smoking when compared to those in the control group using the difference in the pretest and posttest mean attitude scores of the students?

\section{Hypothesis}

The following hypothesis was tested at 0.05 level of significance

1. There is no significant difference in the effect of Cognitive Restructuring technique on secondary school students' attitude towards cigarette smoking, when compared to those in the control group using the difference in the pretest and posttest mean attitude scores.

\section{METHODOLOGY}

\section{Research Design}

This study adopted a quasi-experimental research design. It is a non-randomized pre-test, post-test, control group quasiexperimental research. The study involved two treatment conditions (Experimental and Control group) for the students with predisposing attitude towards cigarette smoking.

\section{Research Setting}

The study was conducted in Awka South Local Government Area of Anambra State. Although there is no available statistics, however, observation have shown that a good 
number of students in Awka South Local government Area of Anambra state are either active or passive smokers and are likely to suffer from a smoking-related illness. Smoking thus could be one of the biggest unidentified causes of death and illness among the youths, especially those in the secondary schools.

\section{Participants}

The sample of the study comprised 62 students purposively selected from a population of 289 students identified with predisposing attitude towards cigarette smoking.

\section{Instrument for Data Collection}

The instrument for data collection is Questionnaire on Cigarette Smoking (QCS). It is an adaptation of the Youth tobacco survey (YTS) and Wisconsin inventory of smoking dependence motive (WISDM-68). The QCS was structured to contain 30- item and to suit the purpose of the study. QCS is divided into two sections A and B. Section A sought for demographic information while section B was used to measure students' attitude towards cigarette smoking. The questionnaire is a 4 point response scale of Strongly Agree (SA) 4points; Agree (A) 3points; Disagree (D) 2points; Strongly Disagree (SD) 1 point. The internal consistency reliability of the instrument using Cronbach's alphas indicated a high reliability coefficient of 0.85 .

\section{Experimental Procedure}

The researcher obtained the approval of the schools' management for carrying on with the research through a consent letter that was given to the management. The experimental training sessions then took place at the two schools chosen for the study. The researcher, with the assistance of the guidance counsellors in the schools conducted a training programme which held for eight weeks for both the treatment and control group. The treatment sessions were carried out in the school's classroom designated as counselling centres. The day and time for each group's training was established and maintained throughout the treatment.

Each training session lasted for 45 minutes using the counselling scheduled periods as specified by the schools. Each of the groups received training for the eight weeks. After the eight weeks of treatments, the instrument "Questionnaire on Cigarette Smoking" (QCS) was re-administered on all the participants in both the experimental and control groups. The scores obtained were stared as the post-test. The post-test scores along with the earlier elicited pre-test scores were then collated and statistically analysed.

\section{Control of Extraneous Variables}

The researcher controlled the possible effect of extraneous variables such as participant's mood, location, discrimination, method, and time of the day which if not well controlled may contaminate the study and possibly interfere with the findings.

\section{Method of Data Analysis}

The completed instruments were scored following the scoring instructions provided as a guide. Data collected was analysed using SPSS version 23. Research question was answered using statistical Mean while the null hypotheses was tested using the Analysis of Co-variance (ANCOVA).

\section{RESULTS}

The data analysed are presented as follows:

\section{Research Question}

What is the effect of Cognitive Restructuring technique on secondary school students' attitude towards cigarette smoking when compared to those in the control group using the difference in the pretest and posttest mean attitude scores of the students?

Table 1: Pre-test and Post-test attitude towards cigarette smoking mean scores of students treated with Cognitive Restructuring technique compared to those treated with conventional counselling $($ Norm= 74.5)

\begin{tabular}{|c|c|c|c|c|c|}
\hline Variables & $\mathrm{N}$ & $\begin{array}{c}\text { Pre-test } \\
\text { Mean }\end{array}$ & $\begin{array}{c}\text { Post-test } \\
\text { Mean }\end{array}$ & $\begin{array}{c}\text { Reduced } \\
\text { Mean }\end{array}$ & $\begin{array}{c}\text { Rema } \\
\text { rk }\end{array}$ \\
\hline $\begin{array}{c}\text { Cognitive } \\
\text { Restructuring } \\
\text { Technique }\end{array}$ & 28 & 80.36 & 63.54 & 16.67 & Effective \\
\hline Control & 31 & 80.84 & 78.23 & 2.61 & \\
\hline
\end{tabular}

Table 1revealed that the students with prone attitude towards cigarette smoking, who were treated with Cognitive Restructuring technique, had pre-test mean score of 80.36 and post-test mean score of 63.54 with reduced mean 16.67 in their attitude rating, while those in the control group who received conventional counselling had pre-test mean score of 80.84 and post-test mean score of 78.23 with reduced mean 2.61. Therefore, with post-test mean score of 63.54 which is below the specified norm of 74.50, Cognitive Restructuring technique is effective in reducing students' prone attitude towards cigarette smoking.

\section{Null Hypothesis}

There is no significant difference in the effect of Cognitive Restructuring technique on secondary school students' attitude towards cigarette smoking, when compared to those in the control group using the difference in the pretest and posttest mean attitude scores.

Table 3: ANCOVA on the effect of Cognitive Restructuring technique on students' attitude towards cigarette smoking compared to those who received conventional counselling

\begin{tabular}{|c|c|c|c|c|c|c|}
\hline Variables & $\begin{array}{c}\text { Sum } \\
\text { of } \\
\text { Squa } \\
\text { res }\end{array}$ & $\begin{array}{c}\mathbf{d} \\
\mathbf{f}\end{array}$ & $\begin{array}{c}\text { Mea } \\
\mathbf{n} \\
\text { Squa } \\
\text { re }\end{array}$ & $\begin{array}{c}\text { Cal } \\
\text {. F }\end{array}$ & $\begin{array}{c}\text { Pv } \\
\mathbf{a l u} \\
\mathbf{e}\end{array}$ & $\begin{array}{c}\text { Decis } \\
\text { ion }\end{array}$ \\
\hline Corrected Model & $\begin{array}{c}3663.36 \\
8 \mathrm{a}\end{array}$ & 2 & $\begin{array}{c}1831.6 \\
84\end{array}$ & & & \\
\hline Intercept & 26.174 & 1 & 26.174 & & & \\
\hline Pretest & 610.861 & 1 & $\begin{array}{c}610.86 \\
1\end{array}$ & & & \\
\hline Treatment_Group & $\begin{array}{c}2896.73 \\
2\end{array}$ & 1 & $\begin{array}{c}2896.7 \\
32\end{array}$ & $\begin{array}{c}249.3 \\
09\end{array}$ & .000 & Sig. \\
\hline
\end{tabular}




\begin{tabular}{|c|c|c|c|c|c|c|}
\hline Error & 650.666 & 56 & 11.619 & & & \\
\hline Total & $\begin{array}{c}305008 . \\
000\end{array}$ & 59 & & & & \\
\hline Corrected Total & $\begin{array}{c}4314.03 \\
4\end{array}$ & 58 & & & & \\
\hline \multicolumn{7}{|c|}{} \\
\hline
\end{tabular}

$\mathrm{P}<0.05$

Table 3 shows that at 0.05 level of significance, $1 \mathrm{df}$ numerator and 58df denominator, the calculated $\mathrm{F}$ is 249.309 with pvalue of 0.000 which is less than the required 0.05 level of significance. Therefore, the null hypothesis is rejected. So, the effect of Cognitive Restructuring technique on secondary school students with prone attitude towards cigarette smoking is significant.

\section{DISCUSSION}

Finding of this study was discussed as follows:

The finding of the study revealed that cognitive restructuring technique was effective in modifying secondary school students' attitude towards cigarette smoking in Awka South local government areas. The finding is an indication that the treatment given to the student participants using cognitive restructuring technique was superior to the treatment given to the participants in the control group who were treated with conventional counselling technique. This finding is in line with previous research efforts such as Hargiana and Keliat (2018), Oguzie, Ani, Obi and Onyegirim (2018), Yunusa, Abdullahi, Oliagba, Sani and Umma (2014) whose studies showed that cognitive restructuring technique is an effective treatment technique for modifying maladaptive behaviours of school children and older adults.

Hargiana and Keliat (2018) reported significant differences in the intervention group for smoking behaviour, some cigarettes consumed, and carbon monoxide levels, before and after CRT such that the average score for smoking behaviour after the intervention was significantly lower. The study found that the group who received treatment using cognitive restructuring technique showed a decrease in smoking behaviour 2.57 times greater at seven days after the intervention than those who were in the control group.

Also, while Oguzie, Ani, Obi and Onyegirim's study reported that cognitive restructuring technique was significantly effective in reducing fear tendency among secondary school students in the experimental group as compared to those in the control group; Yunusa, Abdullahi, Oliagba, Sani and Umma in their study noted that cognitive restructuring intervention on tobacco smoking significantly affected tobacco use cessation among adolescents in secondary schools.

The reason for these findings indicating the efficacy of cognitive restructuring technique could be attributed to the opportunity that CRT offered to the students in identifying negative thoughts and behaviour associated with attitude towards cigarette smoking. This treatment technique focused on the problems they faced in their attempts to change their attitude towards cigarette smoking. This perhaps must have contributed in many ways in understanding and dealing with negative thoughts and attitudinal behaviours.

Moreover, it is possible that since the treatment involved a group counselling therapy sessions that dealt with the concerns of smokers through the use of cognitive behavioural techniques. The group counselling encounter must have provided opportunity for participants to build relationships and help one another overcome life issues related to smoking, and find effective ways to explore and support the changes individuals wish to make in their lives. Also, the research assistants' use of plain language that could be easily understood by the participants and maintaining of focus on the specified problem and purpose may have contributed in building a productive therapeutic relationship for effective implementation of the CRT programme and reception of the treatment by the participants.

\section{CONCLUSION}

Based on the findings of the study, it was concluded from the findings that CRT is an effective treatment technique for modifying cigarette smoking among secondary school students in Awka South LGA.

\section{RECOMMENDATIONS}

Based on the findings of this study and its implications, the following recommendations are made:

1. Practicing counsellors and therapist should make use of the cognitive restructuring technique in counselling and therapy of secondary school students to modifying their unhealthy attitude towards cigarette smoking.

\section{REFERENCES}

[1] Alvarez, H.C. (28 March, 2014). You and cigarettes. Retrieved from you-and-cigarettes.blogspot.md , 2015_06_01_archive

[2] Cacioppo, J. T., Cacioppo, S., \& Petty, R. E. (2018). The neuroscience of persuasion: A review with an emphasis on issues and opportunities. SocialNeuroscience, 13(2),129-172. http://dx.doi.org/10.1080/17470919.2018.1273851

[3] Chandrupatla, S.G., Tavares, M. \& Natto, Z.S. (27 July 2017). Tobacco use and effects of professional advice on smoking cessation among youth in India. Asian Pacific Journal of Cancer $\begin{array}{llll}\text { Prevention, } & 18 & \text { (7), }\end{array}$ doi:10.22034/APJCP.2017.18.7.1861.

[4] Hargiana, G. \& Keliat, B.A. (2018). The effect of cognitive behavioural therapy on heads of families' smoking behaviour and anxiety. Jurnal Keperawatan Indonesia, 21(2), 117-126. DOI: 10.7454/jki.v21i2.770.

[5] Halonen, J.I., Kivimäki, M., Kouvonen, A., Pentti, J., Kawachi, I., Subramanian, S.V., Vahtera, J. (2014). Proximity to a tobacco store and smoking cessation: A cohort study. Tobacco Control, 23(2), 146-151. doi: 10.1136/tobaccocontrol-2012-050726.

[6] Leone, A., Landini, L., \& Leone, A. (2010). What is tobacco smoke? Sociocultural dimensions of the association with cardiovascular risk. Curr Pharm Des., 16(23), 2510-7.

[7] Oguzie, A.E., Ani, D.N., Obi, B.A., Onyegirim, B.O. (2018). Effect of cognitive restructuring technique on fear tendency among secondary school students in Owerri Municipal Council of 
Imo State. International Journal of Advanced Research and Publications, 2(1), 34-38.

[8] Perloff, R.M. (2016). The Dynamics of Persuasion: Communication and Attitudes in the Twenty-First Century, Routledge.

[9] Piko, B.F., Wills, T.A., \& Walker, C. (2017). Motives for smoking and drinking: country and gender differences in samples of Hungarian and US high school students. Addiction Behaviour, 32(20), 87-98

[10] Raja, M., Saha, S., Mohd, S., Narang, R., Reddy, L.V., Kumari, M. (2014). Cognitive Behavioural Therapy versus basic health education for tobacco cessation among tobacco users: A randomized clinical trial. Journal of Clinical and Diagnostic Research JCDR, 8(4), 47-49.

[11] Somers, J. (2017). Cognitive behavioural therapy: Core information document. British Columbia Ministry of Health Retrieved from http://www.health.gov.bc.ca/library/publications/year/2007/MHA Cogniti veBehaviouralTherapy.pdf
[12] Vogel, T., Bohner, G., \& Wanke, M. (2014). Attitudes and attitude change. Psychology Press. West, R., \& Shiffman, S. (2016). Smoking cessation ( $3^{\mathrm{rd}}$ ed.). Abingdon: Health Press.

[13] Webb Hooper, M., Rodríguez de Ybarra, D., \& Baker, E. A. (2013). The effect of placebo tailoring on smoking cessation: A randomized controlled trial. Journal of Consulting and Clinical Psychology, 81(5), 800-809. https://doi.org/10.1037/a0032469

[14] West, R. \& Shiffman, S. (2017). Fast facts: Smoking cessation. Health press Ltd. p. 28. ISBN 978-1-903734-98-8.

[15] World Health Organization (2017). Tobacco fact sheet. Retreieved from

http://www.wpro.who.int/mediacentre/factsheets/fs_201203_tobac colen/

[16] Yunusa, U. Abdullahi, M.I., Oliagba, O. Sani, S. \& Umma, A. (2014). The effect of cognitive restructuring intervention on tobacco smoking among adolescents in senior secondary school in Zaria Kaduna state, Nigeria. European Scientific Journal, 10(5), 327-336. 